\title{
OCHRONOTIC ARTHROPATHY
}

\author{
A Review with Four Case Reports \\ F. H. Laskar and K. D. Sargison, Hull, England \\ From the Royal Infirmary, Hull
}

\begin{abstract}
Alkaptonuria, a rare disorder of amino acid metabolism, is characterised by the excretion in the urine of breakdown products which on oxidation turn black. In some cases the breakdown product, homogentisic acid, is deposited in the tissues. This is called ochronosis. In exceptional cases the deposition in bone and joint leads to the development of ochronotic arthropathy. This paper is presented as a review of the subject, with a description of four new cases.
\end{abstract}

\section{HISTORY}

Alkaptonuria is believed to have been described as early as 1584 (Garrod 1923). Marcet in 1823 (Rose 1957) recorded the case of a patient whose urine caused black stains on the clothing. An accurate account of the condition was given by Boedeker (1859), who described a patient with glycosuria in whom a second reducing substance was found in the urine. This he named "alkapton" on account of its behaviour with alkali. In 1887 Marshall described the first case in the United States of America and discovered alkapton to be glycosuric acid. He described alkaptonuria as an inborn error of metabolism present at birth. In 1891 Wolkow and Baumann isolated glycosuric acid and renamed it homogentisic acid.

Alkaptonuria was classified fully by Garrod (1923), who found the condition to be inherited as a Mendelian recessive characteristic. Hogben, Worrall and Zieve (1932), however, described three families in which the condition appeared as a dominant trait. The first case in Britain was described by Cushing (1925). This case had earlier been recorded by Osler in 1895 (Cushing 1925) as one of Addison's disease. In 1904 Osler described a second case, the brother of the patient described in 1895, and reviewed the cases described throughout the world to that date. In the Continental literature a large monograph was published on alkaptonuria by Poulsen in 1910 .

Ochronosis was first described by Virchow in 1866: during the course of a necropsy he found pigmentation of the tissues, caused by the deposition of ochre-coloured granules. Scleral pigmentation was noted by Osler in 1895 (Cushing 1925), and discoloration of the eyeball fat by Hecker and Wolff in 1889. In 1902 the relationship between ochronosis and alkaptonuria was discovered by Albrecht. In the English literature Pope (1906) gave a fuller description of the findings in ochronosis.

A case of ochronotic pigmentation occurring after the use of phenol dressings on large wounds was found by Pick in 1906 . This variety of ochronotic pigmentation caused by phenol has been termed exogenous ochronosis (Woolley 1952). It probably arises from the alteration of phenolic substances into melanin pigment by the oxidative enzyme tyrosinase.

Ochronotic arthritis-Gross and Allard (1907) noted the striking incidence of arthritic changes in some patients with alkaptonuria, and the pigmentation of joint cartilage was described independently by Clemens (1907), Landois (1908) and Wagner (1908). Four children of an alkaptonuric father who developed severe osteoarthritic changes were recorded by Umber and Bürger in 1913. Radiological changes in the vertebrae and intervertebral discs were demonstrated by Soderbergh in 1915; for these he coined the term "osteitis deformans alkaptonurica".

A survey of the radiological changes in ochronotic arthritis was made by Pomeranz, Friedman and Tunick (1941), who reviewed 100 cases collected to that date. The pathological 
changes in bone and joint and elsewhere were fully described by Hertzberg (1945) and by Lichtenstein and Kaplan (1954).

In the last two decades increasing numbers of cases of this rare disease have been recorded and the hereditary basis of the condition has been clearly established (Hall, Hawkins and Child 1950: Sacks 1951; Black, Lowney and Duffy 1954; Cerveñanský, Sitaj and Urbánek 1959).

\section{ETIOLOGY}

Alkaptonuria with or without ochronosis is a hereditary inborn error of metabolism, inherited as a Mendelian recessive characteristic affecting the breakdown of tyrosine and phenylalanine (Garrod 1923). It is the best example of an error of metabolism inherited as a recessive characteristic (Hogben and colleagues 1932). The condition is due to the absence of the enzyme homogentisate oxygenase in the body (McCollum and Odom 1965).

It is not known why only a small proportion of persons with alkaptonuria develop ochronosis or ochronotic arthritis, but there may be a quantitative relationship between the enzyme defect, the amount of homogentisic acid produced and the deposition of this substance in the soft tissues and joints.

Pigmentation like that of ochronosis has been rarely described in association with a defect of melanin excretion (melanuria) and with the external use of phenol (carboluria) (Oppenheimer and Kline 1922, Sacks 1951).

\section{INCIDENCE}

The occurrence of ochronotic arthropathy has been at various times estimated as from one in forty-three million to one in ten million of the population. These figures probably underestimate the incidence considerably. About 50 per cent of alkaptonurics develop ochronotic arthritis (Eisenberg 1950).

Age and sex incidence-Most cases of ochronosis occur after forty years of age. The youngest patient with ochronosis recorded was aged twenty-three years (Garrod 1923). The peak incidence of ochronotic arthropathy is in the fifth decade (Cervenanský and colleagues 1959). Men are affected more commonly than women in the ratio of about $2: 1$.

\section{BIOCHEMISTRY}

Tyrosine and phenylalanine are metabolised to form their end products, fumaric acid and acetoacetic acid, through the following pathway. Tyrosine and phenylalanine are transaminated to form p-oxyphenyl pyruvic acid and subsequently oxidised to 2:5 dioxyphenylpyruvic acid (homogentisic acid) (Červeňanský and colleagues 1959). This homogentisic acid is further broken down to form diketocarboxylic acid and subsequently hydrolysed enzymatically by "homogentisate oxygenase" to fumaric acid and acetoacetic acid. Fumaric acid is further oxidised to carbon dioxide and water and acetoacetic acid is utilised in the citric acid cycle (Levine, Marples and Gordon 1939; Leslie 1943; Levine, Dann and Marples 1943; Levine, Barnett, Bierman and McNamara 1951; Ravdin and Crandall 1951; Knox and LeMay-Knox 1951 ; Jones, Smith and Evans 1952; Lerner 1953; Bell, Davidson and Scarborough 1965).

In the absence of the enzyme homogentisate oxygenase, homogentisic acid is not broken down and accumulates in the tissues, part being excreted in the urine and sweat (Medes 1932). On exposure to the atmosphere urine and sweat containing homogentisic acid gradually become darkened to a black colour (Fig. 1). In the tissues it is slowly oxidised to form brown-black pigment granules. In the urine the addition of alkali accelerates the colour change (Mitchell 1950).

The reducing properties of homogentisic acid can be detected by the use of Fehling's solution or Benedict's reagent, but this is not specific. Homogentisic acid can be detected specifically by paper chromatography and quantitatively by the iodometric test (Metz 1927; 
Neuberger 1947; Neuberger, Rimington and Wilson 1947; Cain and Berry 1951; Duchŏn, Jirka, Krejči and Richter 1954; Rose 1957; Duncan 1964).

\section{Pathology}

Homogentisic acid is deposited in most of the tissues of the body, which may become pigmented with ochronotic granules. In the joints ochronotic pigment is characteristically deposited in the deeper layers of the articular cartilage, being most pronounced in old cartilage with poor metabolism (Hertzberg 1945, Sacks 1951, Lichtenstein and Kaplan 1954) (Fig. 2). The cartilage loses its elasticity, becomes brittle and stands mechanical strain poorly. The

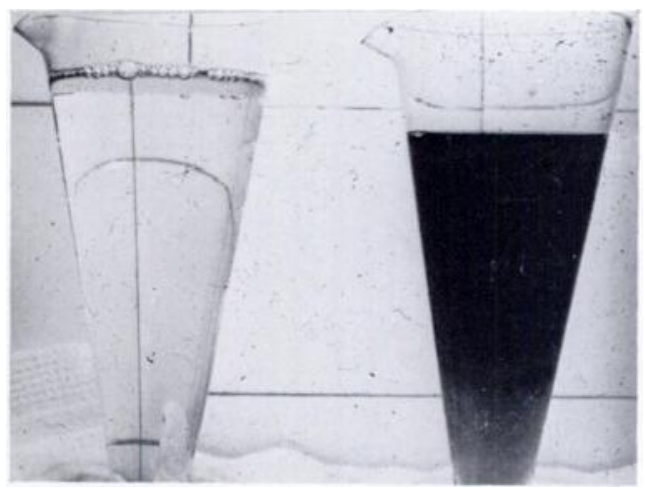

FIG. 1

Darkening of the urine on standing, in a case of ochronotic arthritis (Case 1).

cartilage may thus crack and parts may become separated from the underlying bone to form loose bodies. Small flakes of cartilage become adherent to the synovial membrane causing thickening, fibrosis and chondromatosis. At the reflection of the synovial membrane marginal osteophytes form (Hertzberg 1945, Anderson 1955). Eventually joint irregularity and exposure

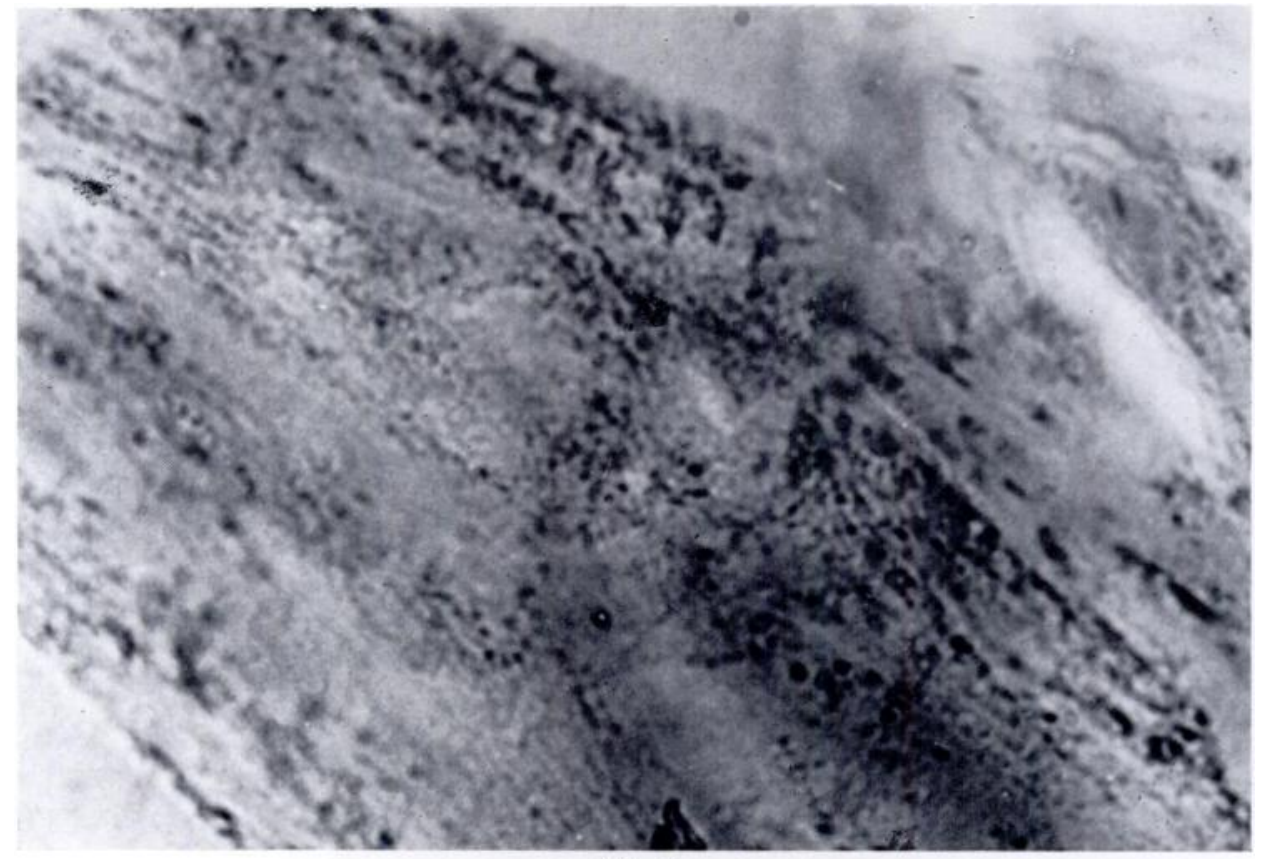

FIG. 2

Section through degenerate articular cartilage of the knee (Case 1). It has become largely fibrocartilaginous, and large numbers of dark staining granules have been deposited between the layers. (Haematoxylin and eosin, $\times 1000$.)

of eburnated bone constitute secondary osteoarthritis. Cyst formation and small bone infarctions may occur adjacent to the joint. The cartilage may disappear completely, so that there is spontaneous bony ankylosis. It has been reported that fragments of pigmented articular cartilage may be forced into adjacent cancellous bone and marrow spaces, becoming surrounded by granulation tissue (Kleinschmidt 1922). Conversely, subchondral bone marrow has been reported as invading the affected articular cartilage. The menisci may become pigmented and secondarily calcified (Soderbergh 1915).

VOL. 52 B, NO. 4, NOVEMBER 1970 
In the vertebral column, intervertebral discs become pigmented and secondarily calcified, evoking marginal osteophytosis of the vertebral bodies. In severe cases the vertebral column may become rigid, superficially resembling the bamboo spine of ankylosing spondylitis (Crissey and Day 1950). The ligaments of the spinal column and its joints may similarly be affected.

The cause of the calcification in the pigmented deposits in menisci, intervertebral discs, ligaments and in tissues such as the ear, trachea, spleen, aorta, prostate, etc., is not known. Homogentisic acid may have an irritant effect (Oppenheimer and Kline 1922, Leslie 1943).

Bone is uncommonly involved but deposition of pigment in the lacunae has been noted, as have fractures through such deposits (Kleinschmidt 1922).

Histopathology-The macroscopic appearance of the tissue involved varies with the severity of the lesion, with the particular tissue involved and the age of the patient. The striking feature is tissue pigmentation, which may vary from brown to black.

Microscopic features-In hyaline cartilage there is deposition of ochre-coloured granules in all layers (Hertzberg 1945), but most markedly in the deeper layers. The cartilage cells are small and pyknotic (Crissey and Day 1950, Lichtenstein and Kaplan 1954) (Fig. 2). In fibrocartilage there may be areas of hyaline degeneration and calcification. The perichondrium may be thickened and pigmented. In the synovium there is thickening and granule deposition, and there may be calcification and small islands of cartilage (Harrold 1956).

\section{CLINICAL FEATURES}

Persons with mild alkaptonuria and ochronosis may pass through life without the condition being recognised. More severe affection may be detected in infancy by the finding that the nappies become darkly stained on exposure to air, or on washing with alkaline soap. A proportion of these more severe cases are first recognised in adult life, commonly by the staining of the clothing at the axilla and by the development of pigmented areas in the ear, sclera or the skin. These pigmented patches, slate grey in colour, appear in the earliest stages in the cochlea and antihelix, and later are seen in the tragus and antitragus. The auricles tend to become rigid. Pigmentation may be noticed on the butterfly area of the face (Garrod 1923). There may be pigmentation of the sclera, appearing as a triangular area with the base towards the cornea. The cornea may become stained; this is best demonstrated by the use of a slit lamp. Staining of the nasal cartilages, knuckles and hypothenar eminence has been described.

Ochronotic arthropathy usually presents in late adult life, the effects becoming more severe with ageing. Many cases previously undetected present as arthritis of the knees or shoulder or as low back pain and stiffness. The first symptoms are usually referred to the spine, the patient complaining of stiffness in the lumbo-sacral region associated with some pain, usually not severe. There may be a gradual extension of the stiffening process throughout the spine, at first with flattening of the lumbar and cervical lordosis, and later with development of kyphosis, commonly at the thoraco-lumbar junction and involving only a short segment of spine. There may be a localised scoliosis or lordosis. The rate of involvement of the whole spine depends on the severity of the disease, but it may be complete within ten years.

Although there may be forward protrusion of the head as a result of neck deformity, movements of the cervical spine usually remain free. Associated with the spinal changes there is a diminution of stature. Stiffness may become severe, suggesting advanced ankylosing spondylitis but without the characteristic severe pain. Increase in the ochronotic degeneration is not associated with a proportional increase in the pain. Occasionally these patients complain of a root type of pain and may present with sciatica. Indeed sciatica has been recorded as the only symptom in ochronotic arthropathy. Intervertebral disc rupture is recorded (Eisenberg 1950, Sacks 1951). 
The muscles become atrophic and occasionally spastic and a posture resembling that in Paget's disease has been noted (Pomeranz and colleagues 1941). It was indeed that which caused Soderbergh (1915) to propose the term "osteitis deformans alkaptonurica".

Chest expansion may be reduced because of involvement of costal cartilages and costovertebral joints. This was seen on one of our cases, though some observers say that it does not occur.

The knees usually become troublesome at a somewhat later stage than the back, although changes may be detected by chance radiography in younger patients. The first symptoms and signs are those of uncomplicated osteoarthritis with pain and swelling. One-third of the patients have an effusion. The knees gradually become stiff and may become deformed, usually in flexion and valgus. The knee may be locked by cartilaginous loose bodies.

In the advanced stages of the disease shoulder stiffness and pain may develop. Hip involvement is an uncommon feature (Rose 1957).

\section{RADIOLOGICAL FINDINGS}

Radiographic changes may precede the onset of symptoms. In the spine the first changes are narrowing of disc spaces, commencing in the thoraco-lumbar region. The vertebral surfaces of the discs become increasingly radiopaque due to calcification, giving a "doubling" of the outline (Červeñanský and colleagues 1959). As the condition progresses the intervertebral discs also become radiopaque, often strikingly so, because of the heavy deposition of calcium. The nucleus pulposus is the last part of the disc to become calcified (Fig. 3). Contrasting with the radiopaque discs the vertebral bodies become porotic. Later they may become deformed by compression. Massive osteophyte formation develops at the vertebral margins and intervertebral bony bridging may occur. Cystic changes may be seen in the vertebral bodies.

Many of these changes may be interpreted as those of ankylosing spondylitis, but the striking density of the intervertebral discs combined with the usual almost complete absence of ligamentous ossification differentiates the conditions. Kyphotic and scoliotic deformity may be seen involving a limited number of vertebral bodies.

In the knees the first changes are those of calcification of the menisci (Figs. 4 and 5). There is increased density in the subchondral region with scattered areas of osteoporosis in the tibial and femoral condyles. The articular surfaces become irregular, the joint space becomes narrowed asymmetrically and marginal osteophytes develop. Calcified loose bodies may be seen. Cysts may occur

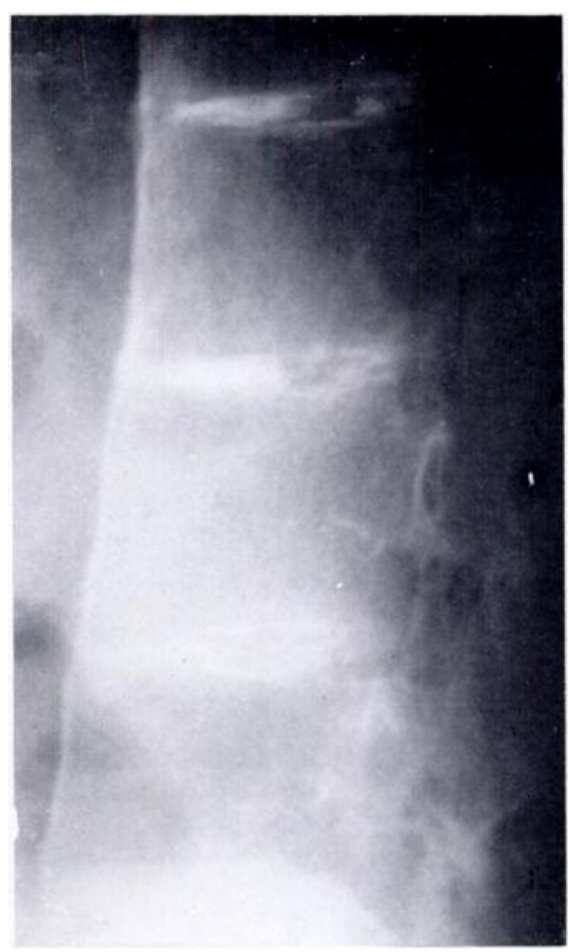

Fig. 3

Radiograph of portion of lumbar spine showing calcification of the intervertebral discs, maximal peripherally, with relative sparing of the nucleus pulposus. in the bone ends, particularly at the attachments of the ligaments and tendons, and sclerotic islands suggestive of avascular necrosis may be present (Figs. 6 and 7).

In the hips and shoulders similar changes occur with flattening of the femoral and humeral heads.

Other radiographic features due to calcified ochronotic deposits include renal calculi, 
prostatic calculi, calcification of the costal cartilages with an irregular spotty appearance, and other soft-tissue opacities (Figs. 8 and 9) (Pomeranz and colleagues 1941).

\section{OTHER INVESTIGATIONS}

Examination of the urine with Fehling's solution or Benedict's reagent demonstrates the presence of a small quantity of a reducing substance. Paper chromatography confirms the

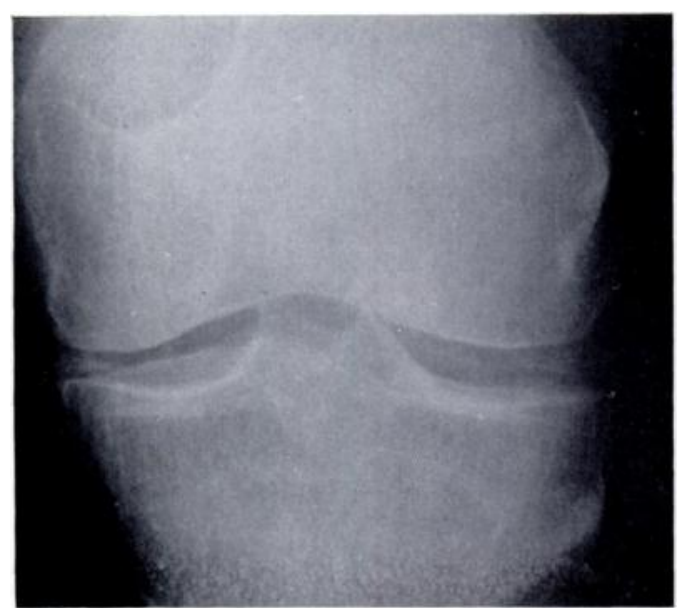

FIG. 4

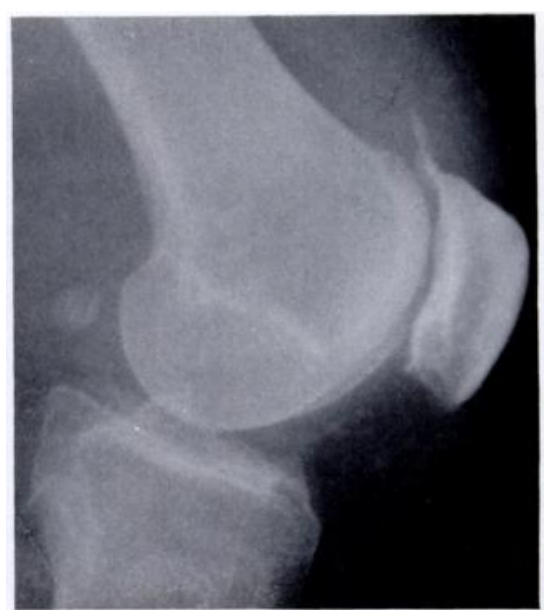

FIG. 5

Figure 4-Antero-posterior radiograph of the knee, showing calcification of the medial and lateral menisci (Case 3). Figure 5-Lateral radiograph of the knee, showing calcification of the menisci, and calcification in the attachment of the quadriceps to the superior pole of the patella (Case 3).

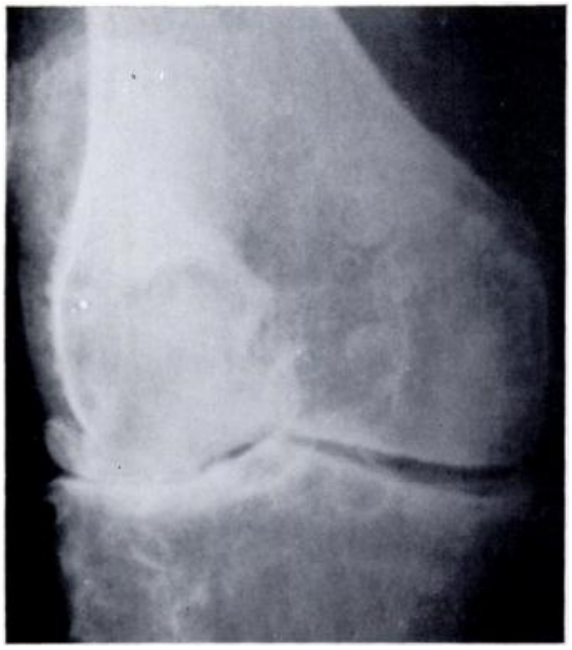

Fig. 6

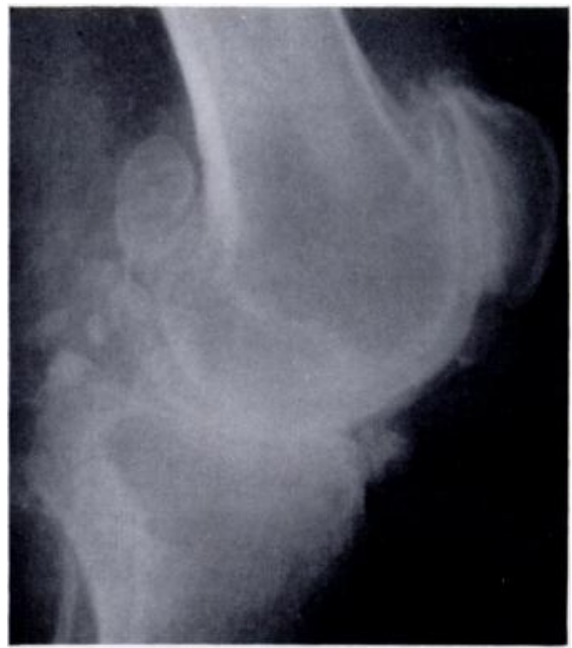

FIG. 7

Figure 6-Radiograph of the knee showing degenerative changes with osteophyte formation, joint space narrowing, cyst formation, and loose bodies (Case 2). Figure 7-Lateral radiograph of the knee joint showing large numbers of loose bodies, osteophyte formation and intraarticular soft-tissue calcification (Case 2).

presence of homogentisic acid (Cain and Berry 1951). The latter may be estimated quantitatively by the iodometric test (Metz 1927). The erythrocyte sedimentation rate is usually within normal limits. The Rose Waaler (sheep cell agglutination) test and latex fixation tests are negative. The Wassermann reaction is sometimes positive. Serum alkaline phosphatase and blood sugar levels are within normal limits. 


\section{DIFFERENTIAL DIAGNOSIS}

Ochronotic arthropathy may resemble osteoarthritis, ankylosing spondylitis, rheumatoid arthritis and osteitis deformans.

In osteoarthritis the spinal involvement is greatest in the lumbar and cervical regions. Disc calcification is unusual. Progressive stiffening of the whole spine does not occur, and restriction of movement in the cervical spine is less pronounced in osteoarthritis. In the

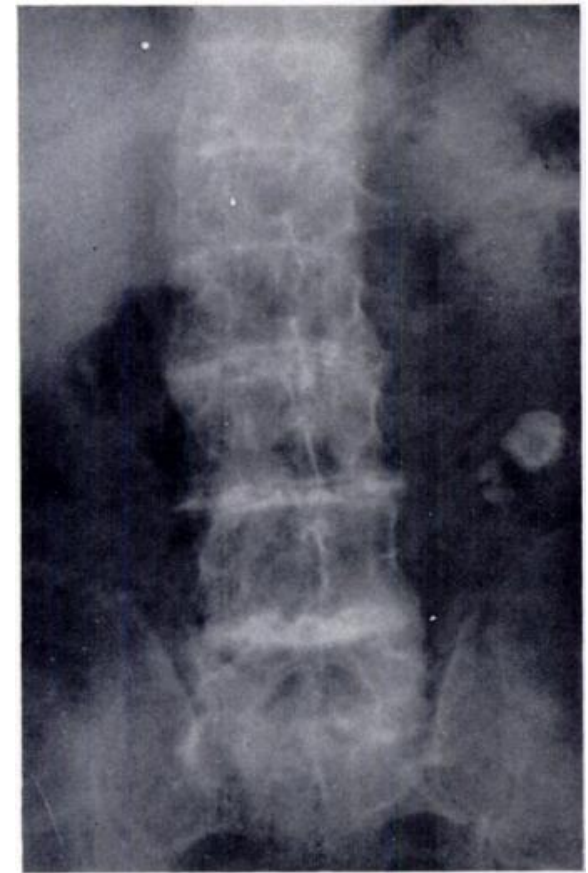

Fig. 8

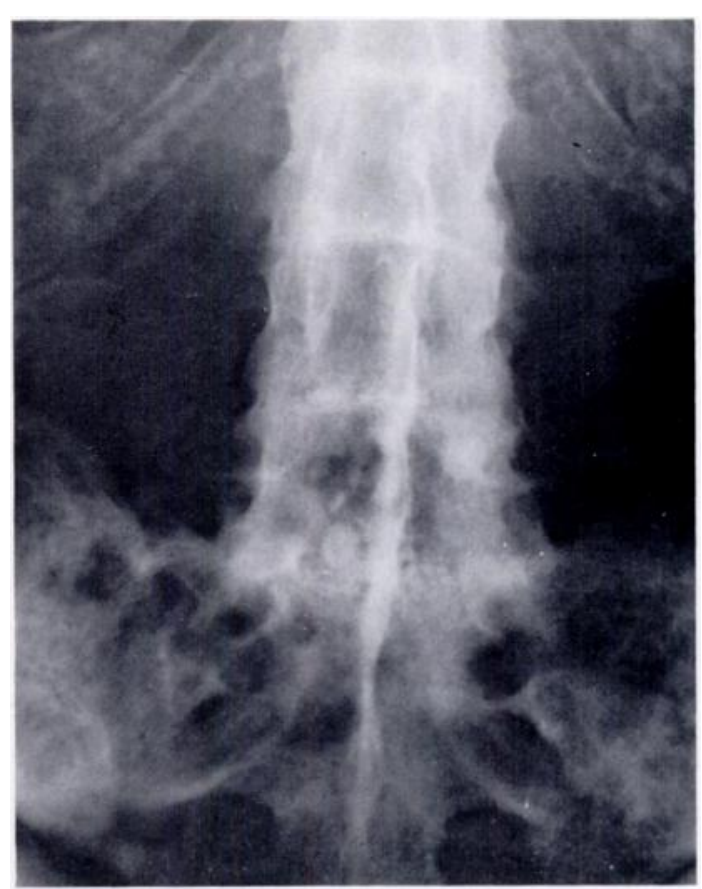

FiG. 9

Figure 8-Radiograph of the lumbar spine showing calcification of the intervertebral discs and lumbar scoliosis. Note the one large and two small renal calculi (Case 1). Figure 9-Radiograph of the lumbar spine showing calcification of the intervertebral discs and heavy calcification of the interspinous ligament. Note also the spotty calcification of the costal cartilage, and sclerosis of the sacro-iliac joints. These appearances superficially resemble those seen in ankylosing spondylitis (Case 2).

peripheral joints differentiation may be more difficult but calcification of the menisci usually gives a clue to the diagnosis. Periarticular calcification may be a distinguishing feature in ochronotic arthritis.

In rheumatoid arthritis the erythrocyte sedimentation rate is raised and specific agglutination tests may be positive. The small joints are usually spared in ochronotic arthropathy. The pain is more severe in rheumatoid arthritis and limitation of neck movement is more marked when the cervical spine is involved.

In ankylosing spondylitis the pain is more severe, cervical rigidity is more marked and the erythrocyte sedimentation rate is typically raised. Radiographically the intervertebral discs are not normally heavily calcified and there is widespread ossification of the spinal ligaments.

Paget's disease has only a superficial resemblance and is readily distinguished radiologically and clinically. In it the serum alkaline phosphatase is usually raised.

\section{COURSE AND PROGNOSIS}

The course and prognosis of the disease depend clearly on the severity of the alkaptonuria. Some cases run a relatively benign course with minimal joint involvement 
throughout life. In more severe cases the patient becomes progressively crippled from increasing spinal deformity and involvement of the knees, shoulders and hips. A few such patients may also become respiratory cripples, spinal deformity and fixity of the costal cartilages leading to decreased vital capacity with liability to respiratory infection. Respiratory difficulty caused by ochronotic arthritis of the crico-thyroid joints leading to fixity of the vocal cords has also been recorded (Červeñanský and colleagues 1959). These patients may be further incapacitated by associated renal, vesical prostatic and biliary calculi. Cardiac failure from calcification of the heart valves may supervene.

\section{TREATMENT}

There is no effective treatment for alkaptonuria. Attempts to modify the metabolic process and to reduce the amount of homogentisic acid produced have been made. Diets free from tyrosine and phenylalanine have been given but without effect.

Vitamin $\mathrm{C}$ is known to play a part in the metabolism of tyrosine and phenylalanine. Ascorbic acid has thus been administered to patients suffering from alkaptonuria and ochronotic arthritis but without any demonstrable effect either on the disease or on the quantity of homogentisic acid excreted (Levine, Marples and Gordon 1939; Sealock and Silberstein 1939; Sealock, Galdston and Steele 1940; Sealock, Perkinson and Basinski 1941; Sealock and Goodland 1951).

Folic acid, vitamin B12 (Levine and colleagues 1951), ACTH, cortisone (Cope and Kassander 1952) and colchicine have been tried without effect, although some patients have symptomatically been improved for a time by ACTH and cortisone.

Methyl thiouracil has been claimed to reduce homogentisic acid formation but there is no conclusive evidence as to its effectiveness (Paschkis, Cantarow, Hart and Rakoff 1944; White, Parker and Block 1949; Sitaj, Urbánek and Weiszer 1953).

Treatment at present is therefore symptomatic by local heat, physiotherapy, analgesics and external support, with surgical treatment in the form of fusion, osteotomy or arthroplasty as indicated.

\section{CASE REPORTS}

Case 1-A man aged sixty had been in good health until a year before his first attendance, though he had had ill-defined low back pain and discomfort in the knees for a few years. A month before the

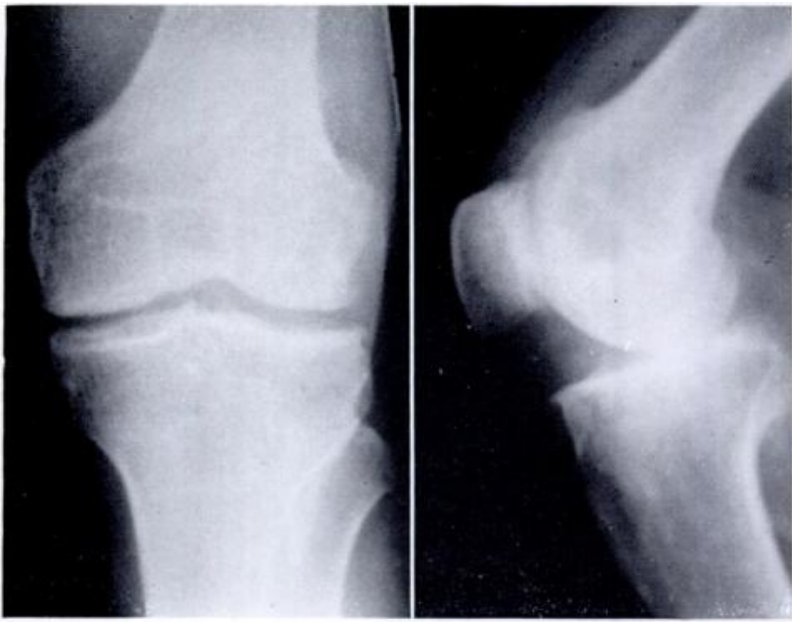

Fig. 10

Case 1-Antero-posterior and lateral radiographs of the right knee showing separation of a portion of bone from the convexity of the medial femoral condyle. first attendance at hospital he developed spontaneous and increasing pain in both knees, more severe on the right. The right knee became locked in flexion on three occasions and was released by self manipulation of the knee. These episodes were associated with pain in the medial aspect of the knee and were followed by an effusion which subsided with rest. The patient also noticed an increase of the long-standing crepitus in the right knee.

Family history-This patient has a moderately large family. Both parents are dead, but there is no known history of arthritic changes of note and there is no suggestion that they suffered from alkaptonuria. The patient has four brothers, one of whom has developed marked backache and pain in the knees during the past few years and has been found to suffer from alkaptonuria with ochronotic arthropathy (see Case 2). The 
other brothers and the two sisters have been shown by radiographic screening and by chromatography to be free from the condition.

Clinical features-The patient was of short stature, 168 centimetres, with a moderate thoracic kyphosis. He stood with a moderate degree of genu varum on both sides, with separation of $7 \cdot 5$

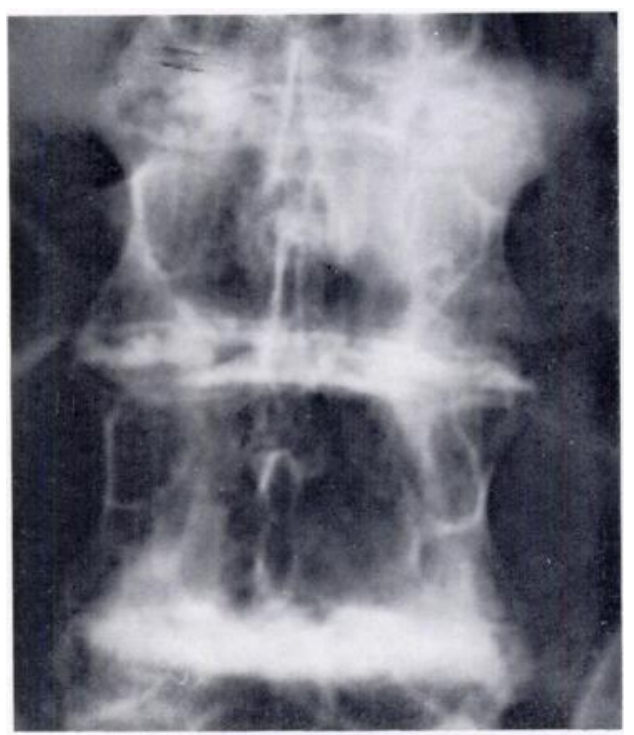

FIG. 11

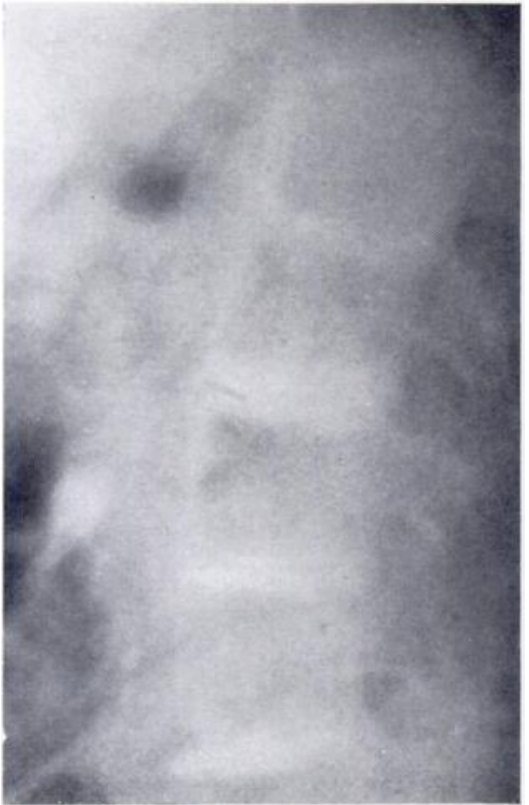

Fig. 12

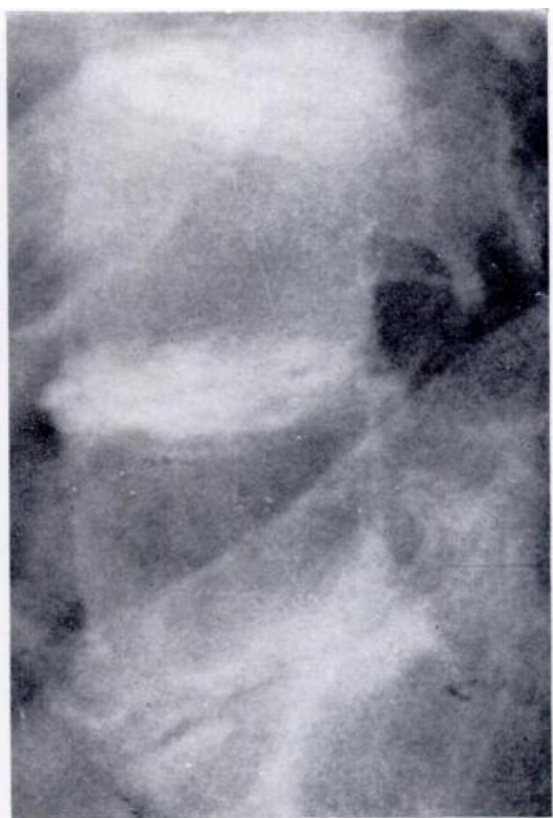

FIG. 13

Case 1-Radiographic appearance of the lumbar spine. Figure 11-Calcification of intervertebral discs and porosis of the vertebral bodies. Figure 12-Lateral radiograph. Note the renal calculus. Figure 13-Characteristic changes at the lumbo-sacral level.

centimetres between the femoral condyles. There was no evidence of skin pigmentation or of deposits of pigment in the sclera, cornea, ears or nasopharynx. Forward flexion of the lumbar spine was two-thirds normal, with some discomfort. In addition to the genu varum there was palpable irregularity of both knees, with crepitus on movement, marked on the right. There was no effusion. The right

VOL. 52 B, NO. 4, NOVEMBER 1970 
quadriceps muscle was wasted. The range of movement in both knees was from 10 to 110 degrees, with pain particularly in the right. All other joints appeared normal.

Radiographs of the knees showed osteoarthritic changes and a loose body on the right (Fig. 10). At this stage the diagnosis had not been suspected, there being no history of darkening of the urine or family history of alkaptonuria.

Operation and progress-The right knee was explored through a medial parapatellar incision. Most of the synovium was found to be heavily stained black. The articular cartilage of the central portion of the medial femoral condyle had disappeared, exposing pigmented underlying bone over an area of 4 centimetres diameter. The surrounding articular cartilage was loosened and was hanging as partially detached fronds. There was a pedunculated portion of articular cartilage about $2 \times 2$ centimetres with

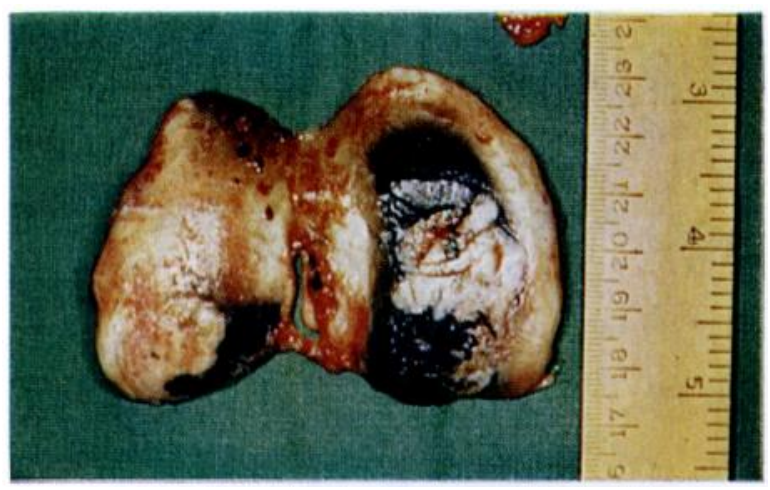

Fig. 14

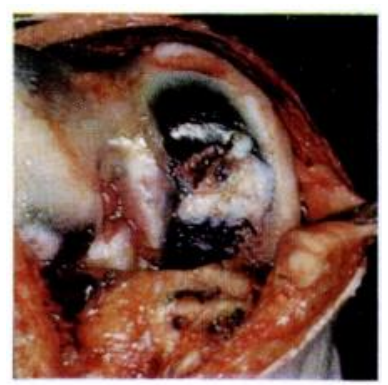

Fig. 15

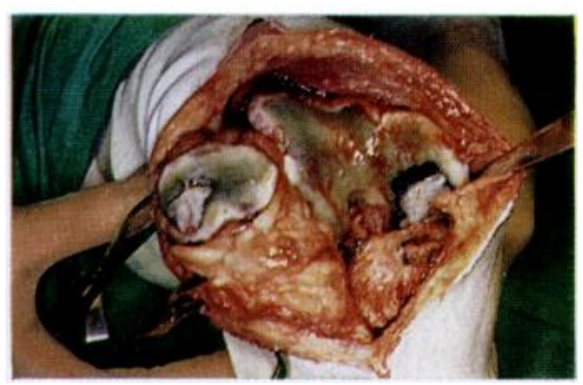

Fig. 16

Case 1-Appearance of the knee joint at the time of fusion. Figure 14-The articular surfaces of the femoral condyles. Note the dark pigmentation of the articular cartilage, particularly over the medial femoral condyle. In the centre of this area a white patch is seen. From here a portion of loose bone and degenerate cartilage had been removed several months previously. Figure 15-The interior of the knee joint, showing pigmentation of most of the articular cartilage, synovium and of the medial femoral condyle. Figure 16-The posterior surface of patella.

a stalk of 3 centimetres attached to the medial margin of the medial femoral condyle. The remainder of the articular cartilage was softened and had a fibrillar appearance. The zone of deepest pigmentation was noted in the deeper layers of the articular cartilage, at the osteochondral junction. There was a large quantity of darkened cartilage debris in the knee. Initially the loose portions of articular cartilage and debris were removed and the edges of the cartilage defect smoothed. Specimens of articular cartilage and synovium were removed for histological examination. This confirmed the diagnosis of ochronotic arthritis (Fig. 2). A specimen of urine voided and allowed to stand turned from straw colour to a blackish-grey colour, and paper chromatography carried out on the urine confirmed the diagnosis of alkaptonuria (Fig. 1).

Radiographs of the lumbar spine showed typical calcification of the intervertebral discs and urinary and prostatic calculi (Figs. 8, 11, 12 and 13). 
The pain in the right knee was not relieved, and ultimately fusion was done. The changes in the articular cartilage are shown in Figures 14 to 16.

Case 2-A man aged sixty-three years at the time of examination had first complained of spontaneous pain in the knees thirteen years previously. Gradually the pain increased and was associated with the gradual development of genu varum, irregularity of the knees and periodic swelling.

Lumbar spinal pain began when the patient was fifty-three. It extended into the thoracic region and was associated with a marked thoracic stoop, progressive stiffness and loss of stature. During this period the patient developed bronchitis and breathlessness on exertion.

Family history-The patient is the brother of the man described in Case 1.

Clinical features-The patient was 165 centimetres in height and showed a marked thoracic kyphosis with secondary increase in the cervical lordosis and forward protrusion of the head. The thoracic kyphosis was regular and there was no scoliosis. There was marked genu varum with separation of 10 centimetres between the femoral condyles. Each knee showed a small effusion and marked palpable irregularity of the joint margins. Movement was from 10 to 90 degrees on each side; there was grating and pain at the extremes of the range of movement. The hips and other joints appeared normal. There was no evidence of skin or scleral pigmentation.

Investigations-The erythrocyte sedimentation rate was 11 millimetres in one hour, and the serum alkaline phosphatase was within normal limits. The Rose Waaler test and latex fixation test for rheumatoid arthritis were negative. The Wassermann reaction was negative. A specimen of urine turned a dark grey on standing and on paper chromatography was found to contain homogentisic acid. Radiographic features - There was dense spotty calcification of the costal cartilages (Fig. 9). The spine showed dense calcification of the intervertebral discs in the lumbar and thoracic regions with calcification of the supraspinous and other intervertebral ligaments. The calcification in the intervertebral discs was most marked at the periphery and tended to spare the central nucleus pulposus (Fig. 3). The sacro-iliac joints were obliterated.

In the knees there was narrowing of the joint spaces medially and laterally with massive peripheral osteophyte formation. There were numerous large loose bodies and the capsular attachments and intra-articular structures were calcified (Figs. 6 and 7).

When this patient was first seen a diagnosis of ankylosing spondylitis was made, but the true nature of the condition was later recognised.

Case 3-A man aged fifty-five years at the time of first examination had been in good health up to two months before he first came to hospital. He had then injured his right knee which for a time was painful and swollen. A month after this he jumped from a height of one metre, twisting his right knee, which again became painful and swollen. This time symptoms did not subside. During the preceding few years the patient had developed a moderate stoop and had occasionally had pain in the lumbar region. He had also noticed a pigmented area over the dorsum of the left hand; this area had grown slowly larger over a period of not less than fifteen years.

Family history-The patient's father, who died at the age of eighty, had in later life developed a marked stoop and had severe arthritis of many joints. His mother is alive and has no arthritis of note. He has one brother who has had no joint trouble. Homogentisic acid was not found in this brother's urine. Clinical features-The patient was 175 centimetres tall and had a slight thoracic kyphosis. The lumbar and cervical spine was fully mobile. In the right knee there was a lax effusion. This was aspirated, 75 millilitres of straw-coloured fluid being withdrawn. There was tenderness over the medial and lateral joint lines and movement was restricted by pain to from 10 to 70 degrees. There was no ligamentous laxity, and no joint irregularity. Two weeks later this effusion had disappeared and there was a painless range of movement of from 0 to 140 degrees. There was no tenderness. The left knee and all other joints appeared normal. On the dorsal aspect of the left hand there was a dark brownish-black area of pigmentation 2 centimetres in diameter. There was no pigmentation of the sclera or conjunctiva.

Investigations-The erythrocyte sedimentation rate was 10 millimetres in one hour. The serum alkaline phosphatase was normal. The Rose Waaler test and latex fixation test for rheumatoid arthritis were negative. The Wassermann reaction was negative. The urine did not turn black on exposure to the air and on prolonged standing, but it was found to contain a reducing substance shown by paper chromatography to be homogentisic acid.

Radiographs of the chest showed no abnormality. In the thoracic spine there were moderate osteoarthritic changes with vertebral body lipping, but there was no sign of intervertebral disc calcification. The lumbar spine showed minor osteoarthritic changes only.

In the knees there was calcification of the menisci on both sides and calcification of the attachment of the quadriceps to the superior pole of the patella. There were some arthritic changes with osteophyte formation particularly at the margins of the patella (Figs. 4 and 5).

VOL. 52 B, NO. 4, NOVEMBER 1970 


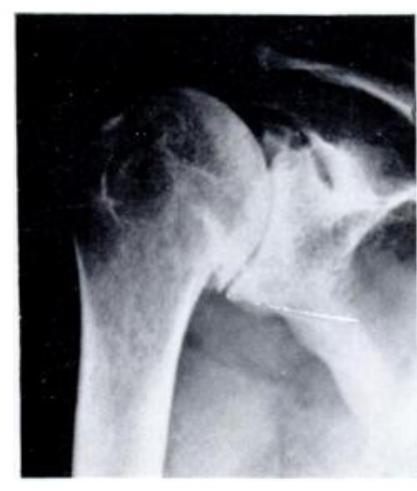

FIG. 17

Case 4-Radiograph of the shoulder showing changes of advanced ochronotic arthritis.

Case 4-A miner aged fifty-eight came with a history of pain and intermittent locking of the knee. He had also pain in the lumbar region and neck with stiffness of the neck and with pain and stiffness of the shoulders. At operation a loose body was found in the knee and was removed; pigmentation of the intra-articular structures was noted. Further investigations confirmed the diagnosis of ochronotic arthropathy, with characteristic changes in the lumbar spine, cervical spine and in the shoulder (Fig. 17). Examination of this patient's family and close relatives was not possible because they lived out of the area.

\section{DISCUSSION}

The increase in the number of reported cases confirms the impression that the incidence of alkaptonuria and ochronotic arthritis has been underestimated in the past. It is, however, impossible to make even a rough estimate of the incidence of this rare condition in Great Britain; here, sporadic cases have been described but no large family group has been documented.

In certain isolated closely inbred communities in central Europe and America a high incidence of alkaptonuria has been observed. The incidence of alkaptonuria and the associated arthritis may therefore differ from country to country, depending upon whether cases occur sporadically or occur in communities.

Previous accounts of ochronotic arthropathy have given the impression that this is a relatively benign condition. Our experience seems to indicate that patients suffering from this disease may be very severely crippled and that the benign nature of the condition has been overemphasised. The increased longevity of patients nowadays may account for this.

In one of our cases the initial radiological diagnosis, which passed unchallenged for some time, was that of ankylosing spondylitis. Unless the possibility of ochronotic arthritis is borne in mind, this misdiagnosis may easily be made. There may indeed be a case for the routine screening - by paper chromatography of the urine-of patients suspected of having ankylosing spondylitis and of other patients showing calcification of the intervertebral discs. In spite of the fact that the costal cartilages and costo-vertebral joints may be involved, there is said to be no reduction of chest expansion in patients with ochronotic arthropathy. In one of our patients with heavy calcification of the costal cartilages there was no detectable chest movement on inspiration. In this case differentiation from ankylosing spondylitis was more difficult than usual.

\section{SUMMARY}

1. Four cases of ochronotic arthropathy have been studied and the related literature has been reviewed.

2. Ochronotic arthropathy is a rare condition resulting from an inborn error of metabolism occurring as a Mendelian recessive characteristic. Its incidence, however, may have been underestimated.

3. Problems of differential diagnosis are discussed and it is suggested that more widespread screening should be undertaken in order to assess the true incidence of the condition.

Our thanks are due to Mr I. Leighton, Chief Technician, Microbiology Department, Hull Royal Infirmary, for help in the preparation of the photomicrographs, and also to $\mathrm{Mr}$ J. Parkes and $\mathrm{Mr} \mathrm{P}$. R. Teasdale, of the Biochemistry Department, Hull Royal Infirmary, for their help in the preparation of paper chromatographs. We are indebted to Dr M. E. Catto, Consultant Pathologist, University Department of Pathology, Western Infirmary, Glasgow, for preparing the histological slides. We are grateful to $\mathrm{Mr}$ J. M. Fitton, Consultant Orthopaedic Surgeon, St James's Hospital, Leeds, for permission to include the fourth case described in the series.

\section{REFERENCES}

Albrf.HT, H. (1902): Ueber Ochronose. Zeitschrift für Heilkunde, 23, 366.

Anderson, C. E. (1955): Hereditary Ochronosis. A Key to the Etiology of Synovial Osteochondromatosis. Journal of Bone and Joint Surgery, 37-A, 642. 
Bell, J. H., Davidson, J. N., and Scarborough, H. (1965): Textbook of Physiology and Biochemistry. Sixth edition. Edinburgh and London: E. \& S. Livingstone Ltd.

BlaCk, R. L., Lowney, J. F., and Duffy, P. M. (1954): Alcaptonuria and Ochronosis. Report of Five Cases Occurring in an American Family. Archives of Internal Medicine, 93, 75.

Boedekfr, C. (1859): Ueber das Alcapton; ein neurer Beitrag zur Frage: Welche Stoffe des Harnes können Kupferreduction bewirken? Zeitschrift für rationelle Medizin, ser 3, 7, 130.

CAIN, L., and Berry, H. K. (1951): In Individual Metabolic Patterns and Human Disease. An Exploratory Study Utilising Predominantly Paper Chromatographic Methods, p. 77. University of Texas Publication No. 5109 Biochemical Institute Studies IV, Austin University of Texas.

Čngveñanský, J., SițaJ, S., and Urbánek. T. (1959): Alkaptonuria and Ochronosis. Journal of Bone and Joint Surgery, 41-A, 1169.

Clemens (1907): Diskussion über Alkaptonurie und Gicht. Verhandlungen des Kongresses für innere Medizin, $24,249$.

Cope, C. B., and Kassander, P. (1952): Cortisone in Ochronotic Arthritis. Journal of the American Medical Association, 150, 997.

CRISSEY, R. E., and DAY, A. J. (1950): Ochronosis. A Case Report. Journal of Bone and Joint Surgery, 32-A, 688.

Cushing, H. (1925): The Life of Sir William Osler. Volume I, p. 623; Volume II, p. 11. Oxford: Clarendon Press.

Duchō̌, J., JiRKA, M., KREJči, E., and Richter, A. F. (1954): Studie o metabolismu kyseling homogentisové. Casopis lékarŭ ćeských, 93, 591.

Duncan, G. G. (ed.)(1942): Diseases of Metabolism: Detailed Methods of Diagnosis and Treatment. Philadelphia: W. B. Saunders Co.

EISENBERG, H. (1950): Alkaptonuria, Ochronosis, Arthritis and Ruptured Intervertebral Disk. Complicated by Homologous Serum Reaction. Archives of Internal Medicine, 86, 79.

Garrod, A. E. (1923): Inborn Errors of Metabolism. Second edition. London: Henry Frowde and Hodder \& Stoughton.

Gross, O., and Allard, E. (1907): Untersuchungen über Alkaptonurie. Zeitschrift für klinische Medizin, $64,359$.

Hall, W. K., Hawkins, K. R., and ChILD, G. P. (1950): The Inheritance of Alkaptonuria in a Large American Family. Journal of Heredity, 41, 23.

Harrold, A. J. (1956): Alkaptonuric Arthritis. Journal of Bone and Joint Surgery, 38-B, 532.

Hecker, A., and Wolff (1889): Ein Fall von Ochronose. Festschrift zur Feier des Fünfzigjährigen Bestehens des Stadt-Krankenhauses zu Dresden-Friedrichstadt, part 2, 325.

HertzberG, J. (1945): On Osteoarthrosis Alkaptonurica (Ochronotica) with Description of One Case. Acta Radiologica, 26, 484.

Hogben, L., Worrall, R. L., and Zieve, I. (1932): The Genetic Basis of Alkaptonuria. Proceedings of the Royal Society' of Edinburgh, 52, 264.

JoNes, J. D., SMITH, B. S. W., and Evans, W. C. (1952): Homogentisic Acid an Intermediate in the Metabolism of Tyrosine by the Aromatic Ringe-Splitting Micro-organisms. Biochemical Journal, 51, xi.

Klfinschmidt, W. (1922): Über einen Fall von endogener "Ochronose bei Alkaptonurie". Frankfurter Zeitschrift für Pathologie, 28, 73.

KNOX, W. E., and LeMAY-Knox, M. (1951): The Oxidation in Liver of L-Tyrosine to Acetoacetate through p-Hydroxyphenylpyruvate and Homogentisic Acid. Biochemical Journal, 49, 686.

LaNdoIs, F. (1908): Zur Kenntnis der Ochronose. Virchows Archiv für pathologische Anatomie und Physiologie und für klinische Medizin, 193, 275.

Lerner, A. B. (1953): Metabolism of Phenylalanine and Tyrosine. Advances in Enzymology, 14, 73.

LESLIE, A. (1943): Alkaptonuria with Hyperuricemia. Archives of Internal Medicine, 71, 68.

Levine, S. Z., Barnett, H. L. Bierman, C. W., and McNamara, H. (1951): Effect of ACTH and Some Adrenocortical Steroids on the Metabolism of Tyrosine and Phenylalanine in Premature Infants. Science, 113, 311.

Levine, S. Z., Dann, M., and Marples, E. (1943): A Defect in the Metabolism of Tyrosine and Phenylalanine in Premature Infants. III. Demonstration of the Irreversible Conversion of Phenylalanine to Tyrosine in the Human Organism. Journal of Clinical Investigation, 22, 551.

I.fvine, S. Z., Marples, E., and Gordon, H. H. (1939): A Defect in the Metabolism of Aromatic Amino Acids in Premature Infants: the Role of Vitamin C. Science, 90, 620.

L.ichtenstein, L., and Kaplan, L. (1954): Hereditary Ochronosis. Pathologic Changes Observed in Two Necropsied Cases. American Journal of Pathology, 30, 99.

McCollum, D. E., and Oром, G. L. (1965): Alkaptonuria, Ochronosis, and Low-Back Pain. A Case Report. Journal of Bone and Joint Surgery, 47-A, 1389.

Marshall (1887): Case Report. Publication of University of Pennsylvania.

Medes, G. (1932): A New Error of Tyrosine Metabolism: Tyrosinosis. The Intermediary Metabolism of Tyrosine and Phenylalanine. Biochemical Journal, 26, 917.

VOL. 52 B, NO. 4, NOVEMBER 1970 
Metz, E. (1927): Eine jodometrische Methode zur Bestimmung der Homogentisinsäure im Harn. Biochemische Zeitschrift, 190, 261.

Mitchell, P. H. (1950): A Textbook of Biochemistry. Second edition. New York: McGraw-Hill Book Company.

Neuberger, A. (1947): Studies on Alcaptonuria. 1. The Estimation of Homogentisic Acid. Biochemical Journal, 41, 431.

Neuberger, A., Rimington, C., and Wilson, J. M. G. (1947): Studies on Alcaptonuria. 2. Investigations on a Case of Human Alcaptonuria. Biochemical Journal, 41, 438.

Oppenheimer, B. S., and Kline, B. S. (1922): Ochronosis; with a Study of an Additional Case. Archives of Internal Medicine, Chicago, 29, 732.

OSLER, W. (1904): Ochronosis. Lancet, 1, 10.

Paschkis, K. E., Cantarow, A., Hart, W. M., and Rakoff, A. E. (1944): Inhibitory Action of Thiouracil, Thiocarbamide and Other Compounds on Melanin Formation by Tyrosinase. Proceedings of the Society for Experimental Biology and Medicine, 57, 37.

Pick, L. (1906): A Case of Ochronosis. Lancet, 1, 1144.

Pomeranz, M. M., Friedman, L. J., and Tunick, I. S. (1941): Roentgen Findings in Alkaptonuric Ochronosis. Radiology, 37, 295.

Pope, F. M. (1906): A Case of Ochronosis. Lancet, 1, 24.

POulSEN, V. (1910): Om ochronotiske tilstande hos mennesker og dyr. Thesis on Ochronosis. Copenhagen, Lund.

Ravdin, R. G., and Crandall, D. I. (1951): The Enzymatic Conversion of Homogentisic Acid to 4-Fumarylacetoacetic Acid. Journal of Biological Chemistry, 189, 137.

Rose, G. K. (1957): Ochronosis. British Journal of Surgery, 44, 481.

SACKs, S. (1951): Alkaptonuric Arthritis. Journal of Bone and Joint Surgery, 33-B, 407.

Sealock, R. R., Galdston, M., and Steele, J. M. (1940): Administration of Ascorbic Acid to an Alkaptonuric Patient. Proceedings of the Society for Experimental Biology and Medicine, 44, 580.

Sealock, R. R., and Goodland, R. L. (1951): Ascorbic Acid, a Coenzyme in Tyrosine Oxidation. Science, 114, 645.

Sealock, R. R., Perkinson, J. D. Jun., and Basinski, D. H. (1941): Further Analysis of the Rôle of Ascorbic Acid in Phenylalanine and Tyrosine Metabolism. Journal of Biological Chemistry, 140, 153.

Sealock, R. R., and Silberstein, H. E. (1939): The Control of Experimental Alcaptonuria by Means of Vitamin C. Science, 90, 517.

Siťaj, S., Urbánek, T., and Weiszer, L. (1953): Experience with Vitamin C and 4-Methyl 2-Thiouracil in Ochronotic Arthropathy. Bratislavske lekarske listy, 33, 1.

SoderberGH, G. (1915): Zur Klinik der Alkaptonurie, insbesondere über die Wassermannsche Reaktion und Ostitis deformans alkaptonurica. Nordiskt medicinskt Arkiv, Afd. 11: Nr. 19, 48, 1.

UMBer, F., and Bürger, M. (1913): Alkaptonurie mit Ochronose und Osteo-Arthritis deformans; Zystinurie. Deutsche Medizinische Wochenschrift, 39, 2337.

Virchow, R. (1866): Ein Fall von allgemeiner Ochronose der Knorpel und knorpelähnlichen Theile. Archiv für pathologische Anatomie und Physiologie und für klinische Medizin, 37, 212.

WAGNER, A. (1908): Ueber Ochronose. Zeitschrift für klinische Medizin, 65, 119.

White, A. G., Parker, J. G., and Block, F. (1949): Studies on Human Alcaptonuria. Effect of Thiouracil, Para-Aminobenzoic Acid and Di-Iodotyrosine on Excretion of Homogentisic Acid. Journal of Clinical Investigation, 28, 140.

Wolkow, M., and Baumann, E. (1891): Homogentisic Acid. Zeitschrift für Physiologische Chemie, 15, 288. Woolley, P. B. (1952): Exogenous Ochronosis. British Medical Journal, 2, 760. 